\title{
Применение психокоррекционных программ повышения профессиональной пригодности персонала исправительных УчрежАений
}

\author{
И. Н. МИНИНА \\ Псковский государственный университет, г. Псков, Российская Федерация \\ ORCID: https://orcid.org/0000-0001-6240-4834, e-mail: irimin@rambler.ru
}

\section{Д. Я. ГРИБАНОВА}

Псковский государственный университет, г. Псков, Российская Федерация

ORCID: https://orcid.org/0000-0002-5633-5876, e-mail: dianab81@mail.ru

\section{Р е ферат}

Введение: в статье рассматриваются результаты применения краткосрочной программы психологической коррекции, включающей профилактику конфликтов и выработку навыков адаптивного поведения в трудных ситуациях общения. Цель: на основе результатов исследования выявить условия эффективности применения психологических программ для преодоления стресса среди сотрудников пенитенциарных учреждений. Методы: решение поставленных в работе задач осуществлялось с применением общенаучных методов исследования в рамках сравнительного, статистического и логического анализа, а также посредством эмпирических методов описания и интерпретации информации. В исследовании приняли участие 80 сотрудников отделов безопасности исправительных учреждений Псковской области, разделенных на экспериментальную и контрольную группы. Тренинги проводились штатными психологами подразделений. Для оценки эффективности использовались методики «Шкала самооценки силы воли» Н. Н. Обозова, определения уровня нервно-психической устойчивости «Прогноз» и опросник межличностных отношений в адаптации В. Щутца. Результаты: анализ данных с использованием методов математической статистики показал, что применение подобных программ целесообразно среди сотрудников, включенных в группу повышенного внимания. Это могут быть лица, условно рекомендованные к данному виду деятельности, а также подвергшиеся деформирующим влияниям неблагоприятной профессиональной среды. Статистически значимым результатом по экспериментальной группе испытуемых стало изменение показателей по шкале искренности, что может означать повышение самооценки, доверия психологу и желания честно отвечать на поставленные вопросы. Наибольшая эффективность тренинга наблюдалась при реализации автором апробированной программы, что объясняется повышенной мотивацией и ответственностью за ее результаты. Среди персонала, изначально имеющего показатели, не требующие коррекции, практического эффекта от участия в тренинге не выявлено. Выводы: для повышения результативности тренингов необходима личная осознанная мотивация специалистов-психологов при разработке уникальных программ, учитывающих реальные потребности персонала обслуживаемых подразделений.

К люче вы е слов а : программа психокоррекции; психологическое сопровождение персонала; сила воли; стресс; психическая устойчивость; тренинг; группа повышенного внимания.

\subsubsection{6 - Юридическая психология.}

Для цитиров ания: Минина И. Н., Грибанова Д. Я. Применение психокоррекционных программ повышения профессиональной пригодности персонала исправительных учреждений. Пенитенциарная наука, 2021, т. 15, № 3 (55), с. 565-574. DOI 10.46741/2686-9764-2021-15-3-565-574. 


\title{
The Use of Psychological Correction Programs to Improve the Occupational Fitness of Correctional Personnel
}

\author{
IRINA N. MININA \\ Pskov State University, Pskov, Russian Federation \\ ORCID: https://orcid.org/0000-0001-6240-4834, e-mail: irimin@rambler.ru
}

\section{DIANA YA. GRIBANOVA}

Pskov State University, Pskov, Russian Federation,

ORCID: https://orcid.org/0000-0002-5633-5876, e-mail: dianab81@mail.ru

\begin{abstract}
Introduction: the article examines the results of the application of a short-term psychological correction program, which includes conflict prevention and the development of adaptive behavior skills in difficult communication situations. Aim: based on the results of the study, to identify conditions for the effective use of psychological programs to overcome stress among prison staff. Methods: the tasks set in the work were solved with the help of general scientific research methods within the framework of comparative, statistical and logical analysis and empirical methods such as description and interpretation of the information. The study involved 80 employees of the security department of correctional institutions of the Pskov Oblast, divided into experimental and control groups. The trainings were conducted by full-time psychologists of the departments. To assess the effectiveness, we used the following methods: "Willpower self-assessment scale" by N.N. Obozov, the technique for determining the level of neuropsychic stability "Forecast", and the questionnaire of interpersonal relations in the adaptation of W. Shchutz. Results: the analysis of the data with the help of mathematical statistics methods has shown that the use of such programs is advisable among employees included in the group of increased attention. These may be persons conditionally recommended for this type of activity, as well as those who have been subjected to the deforming influence of an unfavorable professional environment. A statistically significant result for the experimental group of subjects consisted in a change in the indicators on the sincerity scale, which can mean an increase in self-esteem, trust in the psychologist and the desire to answer the questions honestly. The greatest effectiveness of the training was observed when we were implementing the tested program; this is explained by increased motivation and responsibility for its results. No practical effect of participation in the training was revealed among the personnel who initially had indicators that did not require correction. Conclusions: in order to increase the effectiveness of trainings, it is necessary that psychologists have personal conscious motivation when they work out unique programs that take into account actual needs of correctional staff.
\end{abstract}

Ke y w o rd s: psychological correction program; psychological support of personnel; willpower; stress; mental stability; training; group of increased attention.

19.00.06 - Legal psychology.

For citation: Minina I.N., Gribanova D.Ya. The use of psychological correction programs to improve the occupational fitness of correctional personnel. Penitentiary Science, 2021, vol. 15, no. 3 (55), pp. 565-574. DOI 10.46741/2686-9764-2021-15-3-565-574.

\section{Введение}

Эффективность деятельности пенитенциарных учреждений зависит от уровня профессиональной пригодности личного состава, традиционно принадлежащего к категории лиц с высоким уровнем эмоционально-стрессовых нагрузок. Теоретический анализ отечественной и зарубежной литературы позволил выделить наиболее значимые корреляты рабочего стресса среди сотрудников следственных изоляторов и тюрем. Неоправданная рабочая нагрузка, гипервидимость, восприятие нехватки персонала, проблемы социальных ролей, недостаточный контроль, автономия, отсутствие поддержки на работе или дома, 
подверженность насилию со стороны осужденных оказались наиболее связаны с увеличением стресса среди тюремного персонала служб охраны. В исправительных учреждениях строгого режима основными профессиональными стресс-факторами являются более высокий уровень насилия со стороны заключенных и соотношение сотрудников и осужденных, при котором приходится большее количество заключенных на одного надзирателя $[1 ; 3 ; 7 ; 9 ; 12 ; 13 ; 16]$. Также многоуровневый анализ влияния рабочего стресса, проведенный на выборке из 1800 тюремных служащих, работающих в 45 тюрьмах США, показал, что предполагаемый контроль над заключенными, поддержка со стороны коллег и руководителей положительно влияли на снижение профессионального стресса [15].

Основу пригодности персонала составляют профессиональные качества, которые включают в себя индивидуально-психические и личностные качества индивида, необходимые и достаточные для реализации себя в выбранной профессии. Успешной профессионализации способствуют наличие опыта работы и желание выполнять должностные обязанности на достойном уровне. Многочисленные исследования в разных странах подтверждают значительную взаимосвязь между организационной справедливостью и результатами работы сотрудников системы правосудия [17]. Справедливость можно назвать одним из главных принципов гуманистической системы ценностей и всей человеческой жизнедеятельности. Субъективная оценка сотрудником справедливости отношений является существенным фактором, влияющим на профессиональную мотивацию.

Среднестатистический образ кандидата, которого уголовно-исполнительная система хочет видеть в своих рядах, - это эмоционально зрелый, спокойный, хорошо владеющий собой в различных ситуациях человек от 18 до 40 лет, не поддающийся случайным колебаниям настроения, способный выдерживать большие физические и эмоциональные нагрузки, гибкий в межличностном взаимодействии, склонный идти на компромиссы. Е. И. Кокорина в процессе изучения факторов профессионально-психологической пригодности кандидатов на службу в уголовно-исполнительной системе по результатам психологической диагностики ЦПД ВВК ФКУЗ МСЧ-12 ФСИН России в 2016 г. выявила, что примерно 33 \% из них такими качествами не обладают [3, с. 447].

При изучении вопросов профессиональной пригодности специалиста необходимо учитывать индивидуальные данные человека, его мотивацию и соответствующую служебную подготовку.

Согласно ст. 17 Федерального закона от 19.07.2018 № 197-ФЗ «О службе в уголовноисполнительной системе Российской Федерации и о внесении изменений в Закон Российской Федерации "Об учреждениях и органах, исполняющих уголовные наказания в виде лишения свободы"» на службу должны поступать граждане, «способные по своим личным и деловым качествам, физической подготовке и состоянию здоровья исполнять служебные обязанности сотрудника». Установление соответствия этих качеств и свойств личности кандидата нормативно одобренным требованиям является основной задачей профессионального психологического отбора. А. М. Раков отмечает, что отказ в приеме на службу защищает как самого кандидата от непосильной для него психоэмоциональной нагрузки, так и общество от негативных последствий профессиональной несостоятельности будущего сотрудника. Одновременно данный отбор обеспечивает правовую обоснованность назначения на должность наиболее подходящего кандидата, определяет качества и характеристики, которые следует учитывать и контролировать в процессе профессионального становления [1, с. 104].

В последние десятилетия неизменными остаются два подхода к критериям профессионального психологического отбора:

1. Выявление и отсев кандидатов, имеющих крайне неблагоприятные социально-психологические, индивидуально-психологические или психофизиологические характеристики (отбор по минимуму требований).

2. Выявление и отбор на службу кандидатов, как можно более соответствующих требованиям к профессионально важным качествам (отбор по максимуму требований) [1, с. 108].

Для обеспечения эффективности оперативно-служебной деятельности оптимальным подходом является второй. Он дает возможность выбора лучших из кандидатов, проходящих процедуру отбора. Но реализовать такой подход возможно в учреждениях, в которых отсутствует срочность укомплек- 
тования, нет текучести персонала и поступить на службу в которые желает значительное количество кандидатов.

В настоящее время объективные обстоятельства диктуют реализацию первого подхода при отборе кандидатов на службу в уголовно-исполнительной системе, направленного на профилактику профессиональных деструкций у личного состава. Эти условия приводят к приему на службу лиц, в отношении которых по результатам профессионально-психологического отбора применяется формулировка «условно рекомендуется». Руководство ФСИН России акцентирует внимание на необходимости своевременной профилактики деструктивных явлений среди личного состава учреждений и органов, исполняющих наказания.

Несоответствие индивидуально-психологических качеств специфическим требованиям труда в уголовно-исполнительной системе способствует возникновению у молодых сотрудников психического перенапряжения и, как следствие, различных психосоматических расстройств и заболеваний. Это приводит к неудовлетворенности служебным положением, избранной профессией.

Феномен удовлетворенности работой связан со многими положительными результатами, такими как повышение производительности труда, организационной приверженности, сокращение профессионального выгорания, снижение текучести кадров. Исследования в США, Европе и Китае убедительно демонстрируют, что показатели факторов рабочей среды объясняют большую долю дисперсии в показателе удовлетворенности работой, чем личные характеристики, к которым авторы относят пол, срок пребывания в должности, религию, семейное положение, возраст и уровень образования. Участие персонала исправительных учреждений в принятии решений и разнообразие профессий имели значительные положительные ассоциации, тогда как профессиональная опасность имела значительную отрицательную связь с показателями удовлетворения от выполняемой служебной деятельности [10-12].

Содействовать успешной адаптации сотрудников призваны психологи исправительных учреждений. В арсенале средств психологического воздействия имеются программы, направленные на изменение неадаптивных индивидуально-психологи- ческих качеств личности. Психокоррекционные технологии помогают сотруднику осознать свои привычные неэффективные способы реагирования и на основе осознанного и пережитого личностного материала сформировать способности более эффективно решать свои проблемы, адаптироваться и реализовывать себя в профессиональной деятельности и личной жизни [8, c. 38].

Согласно исследованию польских коллег [14], в котором они проанализировали роль личности, организационных факторов и стратегий преодоления стресса в формировании удовлетворенности работой, социальная чувствительность является предиктором положительного отношения к своей работе сотрудников исправительных учреждений, исправительно-реабилитационного персонала и администрации. Это личностное качество тесно связано с развитием у взрослого человека рефлексии. А наиболее сильным изучаемым предиктором явилась мотивация лидерства и власти, так как в исправительных учреждениях ее реализация персоналом является легко достижимой, а также юридически, психологически и педагогически оправданной.

На важность социального контроля в тюремной жизни указывают и американские психологи. Так, удовлетворенность персонала тюрьмы работой в ней зависит от контроля, который они осуществляют над заключенными, а также осуществления над ними властных полномочий. Ирония этих выводов заключается в том, что те факторы, которые положительно коррелируют с удовлетворенностью работой тюремного персонала, имеют противоположные последствия и соответственно отрицательную корреляцию с вектором восприятия условий отбывания наказания осужденными [11].

\section{Методы}

Анализ практики психологической работы в уголовно-исполнительной системе показывает, что наиболее актуальным психокоррекционным мероприятием для профилактики профессионального выгорания является тренинг по обучению сотрудников методам осознанной психологической саморегуляции, включающий аутогенную и идеомоторную тренировку, нервно-мышечную релаксацию, приемы сенсорного репродуцирования образов, элементы суггестии и др. [9, с. 157-158]. Несмотря на доказанную значимость организационных 
факторов в вопросах снижения профессионального стресса, на переменные рабочей среды пенитенциарные психологи оказывать влияние практически не могут.

На Всероссийском симпозиуме психологов, состоявшемся в Академии ФСИН России в 2019 г., было особо отмечено, что пенитенциарным психологам территориальных органов ФСИН России необходимо не только отчитываться, но и анализировать эффективность влияния психокоррекционных программ на личность сотрудников уголовно-исполнительной системы и осужденных [7, с. 129].

С целью внедрения психологического инструментария для профилактики нежелательных психических состояний и коррекции личностных качеств сотрудников психологами УФСИН России по Псковской области в период с декабря 2019 г. по март 2020 г. была реализована краткосрочная программа психологической коррекции, включающая профилактику конфликтов и выработку навыков и умений адаптивного поведения в трудных ситуациях общения, направленная на повышение психологической устойчивости психоэмоционального состояния личного состава территориальных исправительных учреждений области.

В процессе работы решались следующие задачи:

- выявление личностных качеств и состояний, требующих коррекционного воздействия. Для этого был осуществлен подбор психологических тестов и проведена диагностика уровня выраженности исследуемых характеристик;

- разработка краткосрочной программы психологической коррекции путем подбора тренинговых методов, возможных к реализации среди сотрудников уголовно-исполнительной системы на базе исправительных учреждений;

- апробация программы путем проведения тренинга в экспериментальной группе сотрудников;

- повторное тестирование изучаемых личностных характеристик респондентов экспериментальной и контрольной групп и статистическая обработка полученных результатов.

Всего в исследовании эффективности программы приняло участие 80 сотрудников мужского и женского пола четырех исправительных учреждений УФСИН России по Псковской области. Экспериментальная и контрольная группы состояли из 40 человек, включая мужчин и женщин, так как функциональные обязанности респондентов не учитывали данные различия.

Перед участием в тренинговых мероприятиях было проведено тестирование личного состава с применением методик «Шкала самооценки силы воли (ШСВ)» Н. Н. Обозова, оценки нервно-психической устойчивости «Прогноз» (НПУ) разработки Санкт-Петербургской военно-медицинской академии и опросника межличностных отношений (FIRO) в адаптации B. Щутца.

Результаты

По результатам корреляционного анализа показателей входного тестирования всех респондентов выявлены достоверные взаимосвязи между вспомогательной шкалой оценки искренности L co шкалами силы воли $(r=0,27 ; p<0,01)$ и нервно-психической устойчивости $(r=0,29 ; p<0,01)$. Это говорит о том, что сотрудники, обладающие требуемыми для службы в уголовно-исполнительной системе психическими качествами, более склонны к контролю за сообщаемой информацией и позиционированию своего поведения как социально одобряемого.

Значимо проявилась прямая взаимосвязь нервно-психической устойчивости с основными показателями методики FIRO «Включение» $(r=0,35 ; p<0,01)$ и «Аффект» $(r=0,35 ; p<0,01)$. Психически устойчивые сотрудники способны без ущерба для себя выдерживать большой объем интеракций в связи с включением в различные группы и коллективы. Чем более ценной и значимой личностью сотрудник себя ощущает, тем выше его устойчивость к различным воздействиям субъектов межличностного взаимодействия. Поведение, соответствующее потребности в эмоциональных связях в группах, свидетельствует об установлении дружеских отношений и дифференциации между членами группы. Такие люди стремятся создавать и сохранять чувство теплого эмоционального взаимного отношения. Однако эти личностные характеристики могут провоцировать установление неслужебных связей персонала с осужденными, а также трудности при переводе сотрудников в другие подразделения в интересах службы.

Краткосрочная программа коррекционноразвивающих занятий «Снижение негативных эмоциональных состояний сотрудников отдела безопасности при выполнении служебных обязанностей» (далее - програм- 
ма), разработанная начальником психологической лаборатории ИК-4 О. В. Потаповой, включала на первом этапе упражнения, направленные на снятие блоков и создание комфортных, позитивных взаимоотношений в группе. На втором этапе были проведены занятия по отработке навыков уверенного, эффективного общения на службе, выработке умений анализировать свое состояние, поиску позитивного выхода из различных ситуаций. Третий этап занятий был ориентирован на формирование у участников тренинга уверенности в себе, эмоциональной устойчивости, решительности и самоконтроля при общении с осужденными. Упражнения были направлены на снижение агрессивности и развитие волевой устойчивости. Заключительный этап программы был посвящен обучению навыкам сосредоточения на реакциях собственного тела и отработке различных способов саморегуляции.

Тренинговые мероприятия были реализованы в январе - феврале 2020 г. штатными психологами исправительных учреждений, которыми была также осуществлена обработка результатов входного и контрольного тестирования. Статистическая обработка результатов проведена кафедрой психологии и сопровождения развития ребенка Псковского государственного университета с применением программы SPSS Statistics.

В целом по результатам исследования с помощью Т-критерия Вилкоксона достоверного влияния краткосрочной программы на силу воли и нервно-психическую устойчивость участников тренинга (40 чел.) не выявлено. Такой результат можно объяснить достаточно высокими, не требующими коррекции оценками данных показателей среди большинства респондентов, поступивших на службу после успешного прохождения психологических испытаний. Средние значения ШСВ в экспериментальной группе составляли 7,8土1,6 стенов, в контрольной $6,8 \pm 1,9$ стенов. Однако среди семи участников, имеющих сравнительно низкие тестовые результаты от 4 до 6 стенов, после прохождения программы у пяти выявлен рост среднеарифметических показателей с 5,14 до 6,29 стенов.

Практически все результаты, полученные с применением методики «Прогноз», свидетельствуют о хорошей или достаточной нервно-психической устойчивости профессионального контингента. Средние значения до проведения программы составляли около 6 стенов, и разница в последующих контрольных измерениях не превысила 1 стена.

Однако выявлено достоверное отличие замеров по вспомогательному показателю L (шкала искренности). Получено эмпирическое значение -3,218 при уровне значимости критерия $\mathrm{p}<0,001$. Низкие значения по этой шкале свидетельствуют о том, что испытуемый честно отвечал на вопросы и был уверен в себе.

Таким образом, по реализации Программы в экспериментальной группе произошло изменение показателей по шкале искренно-

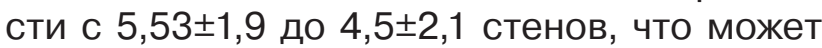
означать повышение самооценки и желания честно отвечать на поставленные вопросы. Такие результаты возможны при росте доверия к психологу и снижении стремления у респондентов казаться лучше, чем они есть на самом деле. Часто высокие показатели по данной шкале среди сотрудников правоохранительных органов свидетельствуют не о недостоверности результатов, а о повышенных требованиях к своему поведению.

Современной науке известны лишь единичные случаи экспериментальной проверки шкал лжи на надежность и валидность измерений. В частности, А. Ю. Мягков указывает на исследование Н. М. Брэдберн и С. Садман (1979), которые попытались ответить на вопрос, действительно ли шкала потребности в социальном одобрении измеряет именно ту латентную переменную, для фиксации которой в свое время была создана. В результате валидационного эксперимента они пришли к выводу, что высокие баллы по результатам тестирования набирают не только респонденты, действительно склонные к социальной желательности, но и люди, имеющие высокие нравственные стандарты и неукоснительно следующие в повседневной жизни конвенциональным нормам. Следовательно, резюмируют авторы, шкала лжи в большей мере фиксирует не склонность испытуемых к искажению ответов на вопросы интервью, а реальные личностные характеристики индивидов, специфику их образа жизни, сознания и поведения [6, с. 66].

В любом случае изменение рассматриваемого показателя является положительным результатом, так как косвенно свидетельствует о снижении психического напряжения у сотрудников исправительных учреждений. 
В показателе нервно-психической устойчивости большое значение имеют основные его психофизиологические корреляты, к которым отнесены сила и баланс нервных процессов, скорость и точность сложной зрительно-моторной реакции, тонус симпатического отдела вегетативной нервной системы, величина кардиоинтервала [4, с. 4]. На них воздействовать в краткосрочный период практически невозможно. Поэтому для изменения психологических коррелят нервно-психической устойчивости, к которым относятся мышление, убеждения, мировоззрение и т. д., требуется более длительный период и качественно иные технологии развития.

В ходе эксперимента были изучены изменения в межличностных отношениях с применением опросника FIRO. По результатам были сформированы два индекса «Объем интеракций» и «Противоречивость межличностного поведения».

Для нормального функционирования индивида необходимо, чтобы существовало равновесие в трех областях межличностных потребностей между ним и окружающими людьми. Поэтому были исследованы предпочитаемая респондентами интенсивность контактов, а также разрыв между собственным и требуемым от окружающих поведением, увеличение которого создает вероятность внутренних конфликтов и фрустрации в области межличностных отношений.

Достоверного влияния краткосрочной программы на характеристики внутри и между отдельными областями межличностных потребностей всех участников тренинга (40 чел.) не выявлено.

При рассмотрении результатов программы на 20 сотрудниках экспериментальной группы с первоначальными значениями индекса «Противоречивость» свыше 5 баллов (вероятность внутреннего конфликта) выявлено снижение средних значений показателей с 7,25 до 5,25 баллов (на 28 \%). Однако в контрольной группе среди сотрудников с первоначальными значениями индекса «Противоречивость» свыше 5 баллов (22 чел.) средний показатель тоже снизился с 6,5 до 5,1 баллов (21\%). Возможно, изменение этих характеристик произошло не по причине практического эффекта участия сотрудников в тренинге.

Проведение программы стимулировало в экспериментальной группе укрепление взаимосвязей показателей силы воли и нервно- психической устойчивости ( $r=0,4 ; p<0,01)$. Это свидетельствует о том, что разработанные упражнения потенциально влияли на изучаемые личностные характеристики. Проявилась взаимосвязь шкалы искренности со шкалой «Требуемое включение» методики FIRO. Чем выше потребность быть замеченным и услышанным, тем более открыт сотрудник в ответах на вопросы и доверителен в отношениях с психологом. Также исчезла тревожная взаимосвязь показателей нервно-психической устойчивости и потребности в дифференциации и близких эмоциональных отношениях.

В процессе первичной статистической обработки результатов эксперимента возникла гипотеза о влиянии на эффективность программы личных и профессиональных качеств психолога-тренера [5, с. 95]. Поэтому были исследованы результаты, полученные в ходе эксперимента в ФКУ ИК-4, штатный психолог которого и разработала краткосрочную программу коррекционно-развивающих занятий.

В этом подразделении по показателям шкалы силы воли у всех участников экспериментальной группы (10 чел.) после тренинга произошло увеличение средних значений

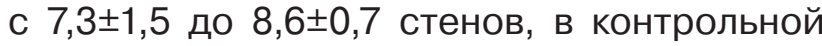
группе (10 чел.) практически все осталось

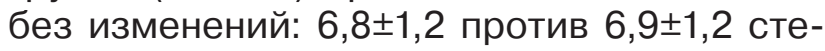
нов.

По показателям нервно-психической устойчивости в экспериментальной группе у всех респондентов произошло увеличение

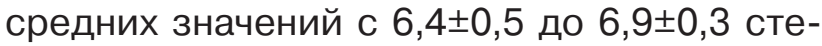
нов, в контрольной группе практически ни-

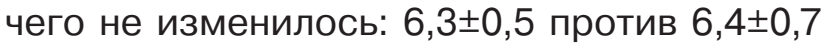
стенов. Индекс искренности в экспери-

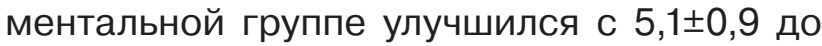
$3,3 \pm 1,3$ стенов, в контрольной ухудшился с

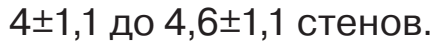

В остальных территориальных подразделениях проведение программы не оказало столь значительных результатов на психоэмоциональное состояние сотрудников.

Таким образом, цель нашего исследования достигнута. Предположение об эффективности разработанной программы для повышения психологической устойчивости психоэмоционального состояния личного состава частично нашло свое подтверждение. Существует вероятность того, что если бы штатный психолог ИК-4, регулярно повышающая свою профессиональную квалификацию, проводила бы тренинги во 
всех исправительных учреждениях области, то результативность апробируемой краткосрочной программы для коррекции показателей ШСВ и НПУ среди всего личного состава оказалась бы выше и статистически значимой.

\section{Заключение}

В настоящее время основная работа психологов исправительных учреждений с личным составом заключается в проведении диагностических процедур при приеме кандидатов на службу и психологическом сопровождении профессиональной деятельности. Хотя психологическая коррекция является одним из основных регламентированных видов деятельности психологов уголовно-исполнительной системы, проведение подобных мероприятий является скорее исключением из правил, чем повседневной работой. Этому способствует недостаточная штатная численность психологов на протяжении всей истории создания и функционирования психологической службы. По авторитетному мнению М. Г. Дебольского, минимальная штатная численность психологических лабораторий в два человека «хотя и не позволяет осуществлять психологическое обеспечение работы с осужденными и персоналом в полном объеме, но дает возможность решать наиболее актуальные психологические проблемы, осложняющие оперативную обстановку в учреждении» [2, c. 126].

Учитывая необходимость целесообразного распределения служебного времени специалистов-психологов, можно рекомендовать проведение психокоррекционных мероприятий с сотрудниками со сниженными показателями силы воли и нервно-психической устойчивости, то есть относящимися к группе повышенного внимания.

Итоги экспериментального внедрения программы свидетельствуют о том, что ее эффективность зависит в большей степени от профессионализма, мотивации и заинтересованности практикующего психолога в ее результатах. Поэтому для повышения результативности психологического сопровождения деятельности работников ФСИН России можно рекомендовать прохождение психологами обучения по программам дополнительного профессионального образования. Полезным может оказаться применение материального стимулирования участия в конкурсах профессионального мастерства.
В развитых зарубежных странах количество специалистов-психологов, привлекаемых к психологическому сопровождению работников, значительно отличается в большую сторону. Централизованно разрабатываются программы и стратегии борьбы со стрессом среди сотрудников исправительных учреждений, при апробации и внедрении которых эксперты по стрессу могут предоставить помощь в настройке или улучшении стресспрограмм. Так, при внедрении данного психологического инструментария на территории штата Вашингтон (США) департаментом юстиции рекомендовано учесть несколько факторов, чтобы сделать свои программы эффективными. Например:

- назначить талантливых и преданных своему делу психологов, которые выдержат стресс помощи, оказываемой другим сотрудникам, его испытывающим;

- добиться искреннего участия высшего руководства, профсоюзных и линейных руководителей, а также членов семьи сотрудников, нуждающихся в психологической помощи и коррекции психических состояний;

- соблюдать конфиденциальность в своей работе;

- при предоставлении услуг работать системно, а не только разбирая ситуации после критических происшествий;

- обучить руководителей выявлять сотрудников, которые могут испытывать стресс и нуждаются в консультации психолога;

- в случае необходимости сменить должность или исправительное учреждение таким образом, чтобы снизить стресс сотрудника;

- проводить мониторинг программных мероприятий и оценку их эффективности в снижении стресса и повышении эффективности работы подразделения [13, с. 129].

В 2014 г. в ходе Национального симпозиума по проблемам работников исправительных учреждений США ведущими специалистами органов здравоохранения и подразделений юстиции отмечалось, что, несмотря на значительные местные усилия и рекомендуемые передовые практики, нет разработанной универсальной программы для тюремного персонала с доказанной эффективностью и безопасностью. Поэтому необходимы дополнительные исследования в области благополучия, физического и психологического здоровья сотрудников, работающих с осужденными [16]. 
Таким образом, распространение передового опыта психокоррекционной деятельности с персоналом исправительных учреждений возможно только путем ознакомления и добровольного осмысленного применения психологами рекомендованных тренинговых мероприятий. Вынужденное внедрение чужих наработок не может обеспечить гарантированного положительного результата. Эти мероприятия должны мотивировать специалистов-психологов к разработке уникальных программ, учитывающих реальные потребности персонала обслуживаемых подразделений.

\section{СПИСОК ЛИТЕРАТУРЫ}

1. Бовин, Б. Г. Профессионально-психологический отбор в уголовно-исполнительной системе России и его эффективность / Б. Г. Бовин, А. М. Раков // Прикладная юридическая психология. - 2009. - № 2. - С. 104-114.

2. Дебольский, М. Г. Психологическая служба уголовно-исполнительной системы России: опыт организации / М. Г. Дебольский // Российский психологический журнал. - 2004. - № 1. - C. 119-130. - URL: https://www.elibrary.ru/ download/elibrary_16344754_14186837.pdf (дата обращения: 12.07.2020).

3. Кокорина, Е. И. Профессионально-психологическая пригодность кандидатов к службе в УИС / Е. И. Кокорина // Novalnfo.Ru. - 2017. - № 65. - C. 444-447. - URL: https://novainfo.ru/pdf/065-1.pdf (дата обращения: 12.07.2020).

4. Корзунин, А. В. Психофизиологические критерии оценки нервно-психической устойчивости в процессе военнопрофессиональной адаптации военнослужащих : автореферат диссертации на соискание ученой степени кандидата медицинских наук / А. В. Корзунин. - Санкт-Петербург, 2015. - 24 с.

5. Красненкова, С. А. К вопросу о современном состоянии психокоррекционной работы в пенитенциарной практике / С. А. Красненкова // Прикладная юридическая психология. - 2008. - № 4. - С. 93-98.

6. Мягков, А. Ю. Шкалы лжи: опыт социологической реинтерпретации / А. Ю. Мягков // Вестник ИГЭУ. - 2006. № 1. - C. 66-73. - URL: https://cyberleninka.ru/article/n/shkaly-Izhi-opyt-sotsiologicheskoy-reinterpretatsii (дата обращения: 13.07.2020).

7. Овчарова, Е. В. Современные психокоррекционные и психотерапевтические направления в работе пенитенциарных психологов / Е. В. Овчарова // Психология XXI века: вызовы, поиски, векторы развития : тезисы докладов Всероссийского симпозиума психологов (Рязань, 5 апреля 2019 г.). - Рязань : Академия ФСИН России, 2019. C. $125-129$.

8. Федорова, Е. М. Основные формы и методы психологической профилактики и коррекции профессиональных деструкций личного состава УИС / Е. М. Федорова // Ведомости уголовно-исполнительной системы. - 2016. - № 4 (167). - С. 34-39.

9. Черкасова, М. А. Психологический мониторинг профессионального выгорания сотрудников Уис России : диссертация на соискание ученой степени кандидата психологических наук: 19.00 .06 / М. А. Черкасова. - Вологда, 2014. - $187 \mathrm{c}$.

10. An exploratory study of the effects of work environment variables on job satisfaction among Chinese prison staff S. Jiang, E.G. Lambert, J. Liu, J. Zhang // International Journal of Offender Therapy and Comparative Criminology. 2018. - Volume 62 (6). - Pp. 1694-1719.

11. Blau, Ju. R. Individual and Contextual Effects on Stress and Job Satisfaction: A Study of Prison Staff/ Ju. R. Blau, S. C. Light, M. Chamlin // Work and Occupations. - 1986. - Volume 13 (1). - Pp. 131-156. - DOI 10.1177/0730888486013001009.

12. Ellison, J. M. Working on local time: Testing the job-demand-control-support model of stress with jail officers / J. M. Ellison, J. W. Caudill // Journal of Criminal Justice. - 2020. - Volume 70 (C). - DOI 10.1016 / j.jcrimjus.2020.101717. 13. Finn, P. Addressing Correctional Officer Stress: Programs and Strategies / Peter Finn. - Washington, DC : U.S. Department of Justice, 2000. - $134 \mathrm{c}$.

14. Sygit-Kowalkowska, E. Predicting the Role of Personality Traits, Organizational Factors, and Strategies for Coping with Stress in Job Satisfaction in Correctional Services / E. Sygit-Kowalkowska, R. Poklek, B. Pastwa-Wojciechowska // Polish Psychological Bulletin. - 2020. - Vol. 50. - Pp. 275-283. - DOI 10.24425/ppb.2019.130701.

15. Steiner, B. Individual and Environmental Sources of Work Stress Among Prison Officers / B. Steiner, J. Wooldredge // Criminal Justice and Behavior. - 2015. - Volume 42(8). - Pp. 800-818. - DOI 10.1177 / 0093854814564463.

16. Stress and corrections: Addressing the safetyand well-being of correctional officers / D. Elliot, K. Kuehl, M. Ghaziri, M. Cherniack // Corrections Today. - 2015. - Volume 77 (4) - Pp. 40-44.

17. Wolfe, S. E. The organizational justice effect among criminal justice employees: A meta analysis / S. E. Wolfe, S. G. Lawson // Criminology. - 2020. - Volume 58 (2). - DOI 10.1111/1745-9125.12251.

\section{REFERENCES}

1. Bovin B.G., Rakov A.M. Professional psychological selection in the penal system of Russia and its effectiveness. Prikladnaya yuridicheskaya psikhologiya=Applied Legal Psychology, 2009, no. 2, pp. 104-114. (In Russ.).

2. Debol'skii M.G. Psychological service of the penal system of Russia: the experience of organization. Rossiiskii psikhologicheskii zhurnal=Russian Psychological Journal, 2004, no. 1, pp. 119-130. Available at: https://www.elibrary.ru/ download/elibrary_16344754_14186837.pdf (accessed July 12, 2020). (In Russian).

3. Kokorina E.I. Professional psychological suitability of candidates for service in the penal system. Novalnfo.Ru, 2017, no. 65, pp. 444-447. Available at: https://novainfo.ru/pdf/065-1.pdf (accessed July 12, 2020). (In Russian).

4. Korzunin A.V. Psikhofiziologicheskie kriterii otsenki nervno-psikhicheskoi ustoichivosti $v$ protsesse voennoprofessional'noi adaptatsii voennosluzhashchikh: avtoreferat dissertatsii na soiskanie uchenoi stepeni kandidata meditsinskikh nauk [Psychophysiological criteria for the assessment of neuropsychological stability in the process of military professional adaptation: Candidate of Sciences (Medicine) dissertation abstract]. Saint Petersburg, 2015. 24 p. 5. Krasnenkova S.A. On the issue of the current state of psychological correction work in penitentiary practice. Prikladnaya yuridicheskaya psikhologiya=Applied Legal Psychology, 2008, no. 4, pp. 93-98. (In Russ.). 
6. Myagkov A.Yu. Falsehood scales: the attempt of sociological reinterpretation. Vestnik IGEU=Vestnik of Ivanovo State Power University, 2006, no. 1, pp.66-73. Available at: https://cyberleninka.ru/article/n/shkaly-lzhi-opyt-sotsiologicheskoyreinterpretatsii (accessed July 13, 2020). (In Russ.).

7. Ovcharova E.V. Modern psychological correction and psychotherapeutic directions in the work of penitentiary psychologists. In: Psikhologiya XXI veka: vyzovy, poiski, vektory razvitiya: tezisy dokladov vserossiiskogo simpoziuma psikhologov (Ryazan', 5 aprelya 2019 g.) [Psychology of the 21st century: challenges, search, vectors of development: Abstracts of the All-Russian Symposium of Psychologists (Ryazan, April 5, 2019)]. Ryazan: Akademiya FSIN Rossii, 2019. Pp. 125-129. Available at: https://www.elibrary.ru/item.asp?id=37275422\& (accessed July 17, 2020). (In Russ.).

8. Features of the organization and prospects for the development of psychological work with the personnel of the penal system within the framework of the implementation of the provisions of the Concept for development of the penal system of the Russian Federation until 2020: decision of the Board of the Federal Penitentiary Service of Russia. In: Ob ob"yavlenii reshenii kollegii Federal'noi sluzhby ispolneniya nakazanii: prikaz FSIN Rossii ot 07.12.2012 [On the announcement of decisions of the boards of the Federal Penitentiary Service: Order of FSIN Russia dated December 7, 2012]. (In Russ.).

9. Fedorova E.M. The main forms and methods of psychological prevention and correction of professional destruction of correctional personnel. Vedomosti ugolovno-ispolnitel'noi sistemy=News of the Penal System, 2016, no. 4 (167), pp. 3439. Available at: https://www.elibrary.ru/download/elibrary_26470782_20126321.pdf (accessed July 10, 2020). (In Russ.). 10. Cherkasova M.A. Psikhologicheskii monitoring professional'nogo vygoraniya sotrudnikov UIS Rossii: dissertatsiya na soiskanie uchenoi stepeni kandidata psikhologicheskikh nauk: 19.00.06 [Psychological monitoring of professional burnout of employees the penal system of Russia: Candidate of Sciences (Psychology) dissertation]. Vologda, 2014. 187 p.

11. Jiang S., Lambert E.G., Liu J., Zhang J. An exploratory study of the effects of work environment variables on job satisfaction among Chinese prison staff. International Journal of Offender Therapy and Comparative Criminology, 2018, vol. 62 (6), pp. 1694-1719.

12. Blau Ju.R., Light S.C., Chamlin M. Individual and contextual effects on stress and job satisfaction: a study of prison staff. Work and Occupations, 1986, vol. 13(1), pp. 131-156. DOI: 10.1177/0730888486013001009.

13. Ellison J. M., Caudill J.W. Working on local time: testing the job-demand-control-support model of stress with jail officers. Journal of Criminal Justice, 2020, vol. 70 (C). DOI: 10.1016 / j.jcrimjus.2020.101717.

14. Finn P. Addressing correctional officer stress: programs and strategies. Washington, DC: U.S. Department of Justice. 2000. Available at: https://files.eric.ed.gov/fulltext/ED449457.pdf (accessed January 9, 2021).

15. Sygit-Kowalkowska E., Poklek R., Pastwa-Wojciechowska B. Predicting the role of personality traits, organizational factors, and strategies for coping with stress in job satisfaction in correctional services. Polish Psychological Bulletin, 2020, vol. 50, pp. 275-283. DOI: 10.24425/ppb.2019.130701.

16. Steiner B., Wooldredge J. Individual and environmental sources of work stress among prison officers. Criminal Justice and Behavior, 2015, vol. 42 (8), pp. 800-818. DOI: 10.1177 / 0093854814564463.

17. Elliot D., Kuehl K., El Ghaziri M., Cherniack M. Stress and corrections: addressing the safety and well-being of correctional officers. Corrections Today, 2015, vol. 77 (4), pp. 40-44.

18. Wolfe S.E., Lawson S.G. The organizational justice effect among criminal justice employees: a meta analysis. Criminology, 2020, vol. 58 (2). DOI: 10.1111/1745-9125.12251.

\section{CВЕДЕНИЯ ОБ АВТOPAX / INFORMATION ABOUT THE AUTHORS}

ИРИНА НИКОЛАЕВНА МИНИНА - кандИДат пСИХОЛОгических наук, доцент кафедры психологии и сопровождения развития ребенка Псковского государственного университета, г. Псков, Российская Федерация, ORCID: https://orcid.org/0000-0001-6240-4834, e-mail: irimin@ rambler.ru

ДИАНА ЯРОСЛАВОВНА ГИБАНОВА - КандИдат псИХологических наук, доцент кафедры психологии и сопровождения развития ребенка Псковского государственного университета, г. Псков, Российская Федерация, ORCID: https://orcid.org/0000-0002-5633-5876, e-mail: dianab81@mail.ru
IRINA N. MININA - Candidate of Sciences (Psychology), associate professor of the Department of Psychology and Child Development Support at Pskov State University, Pskov, Russian Federation, ORCID: https://orcid.org/00000001-6240-4834, e-mail: irimin@rambler.ru

DIANA YA. GRIBANOVA - Candidate of Sciences (Psychology), associate professor of the Department of Psychology and Child Development Support at Pskov State University, Pskov, Russian Federation, ORCID: https://orcid. org/0000-0002-5633-5876, e-mail: dianab81@mail.ru 